\title{
A prehistoric pyramid in the shape of a volcanic cinder cone, Nepeña Valley, Peru
}

\author{
Robert A. Benfer ${ }^{1, *} \&$ Andrés Ocás ${ }^{2}$
}

Archaeological work in the 1960s in the middle Nepeña Valley of coastal Peru (Figure 1) identified an artificial earthen mound or pyramid, approximately $15.5 \mathrm{~m}$ high, with what was interpreted to be a crater dug into the top (Proulx 1968). This site has been variously known as Wanka, Huaca de Muro and El Bocón (PV31-55 in the Peruvian Ministry of Culture files). When viewed from a distance (Figure 2), the site resembles a volcanic cinder cone, such as the one in the Andahua Valley in southern Peru (Figure 3), and we have therefore named the site El Volcán. It should be noted, however, that there are no volcanoes in the vicinity of El Volcán to serve as models, nor indeed are any other examples of volcanoshaped structures known from Peru or elsewhere.

The mound has been affected by recent disturbances including bulldozing on the northeast face, a modern field wall on the south-east face and a cut for a pigsty on the north-west face (Figure 3). Our excavation trench is located on the south wall of the crater. Figure $4 \mathrm{~A}$ shows a collapsed stairwell that descends beneath, and thus pre-dates, a row of adobe bricks (Figure 4B). Two metres below the surface, and the adobe bricks, is a fragment of a mudplaster floor. The fill in the trench comprised large- and medium-sized stones and dirt (Figure $5 \mathrm{~A}$ is a profile of the cut in Figure 4). A hearth was located $2 \mathrm{~m}$ below the centre of the inner cone (Figure 5B). The hearth contained charcoal and shell along with a mudpacked floor; adobe bricks were also found in the trench at the same depth. The date at which the pyramid was first constructed is currently unknown, although the site's proximity to the Late Formative centre (900 BC-200 BC) of San Isidrio (Chicoine \& Ikehara 2014) is suggestive. Surface ceramics from San Isidrio resemble some of those found at El Volcán, but these lack context and may have been imported to the site with soil from nearby areas.

At this early stage of investigation, the El Volcán site presents a conundrum. The unusual shape of the pyramid merits note, but it is not obvious what might have prompted its construction or what activities might have taken place there. Two main explanations have been put forward, one arguing that later looting or erosion has created the site's distinctive form, and the other that the site was originally constructed to resemble a volcanic cone and can be linked to astronomical events and ethnohistorical accounts. We offer five arguments against the suggestion that subsequent activities or processes have altered a typical rectangular pyramid into a circular form:

\footnotetext{
Department of Anthropology, University of Missouri, Columbia, MO 65211, USA

Asociación Nueva Amistad Mz.E, Lt 10, Los Olivos, Lima, Perú (Email: andresocas@gmail.com)

Author for correspondence (Email: benferr@missouri.edu)
} 


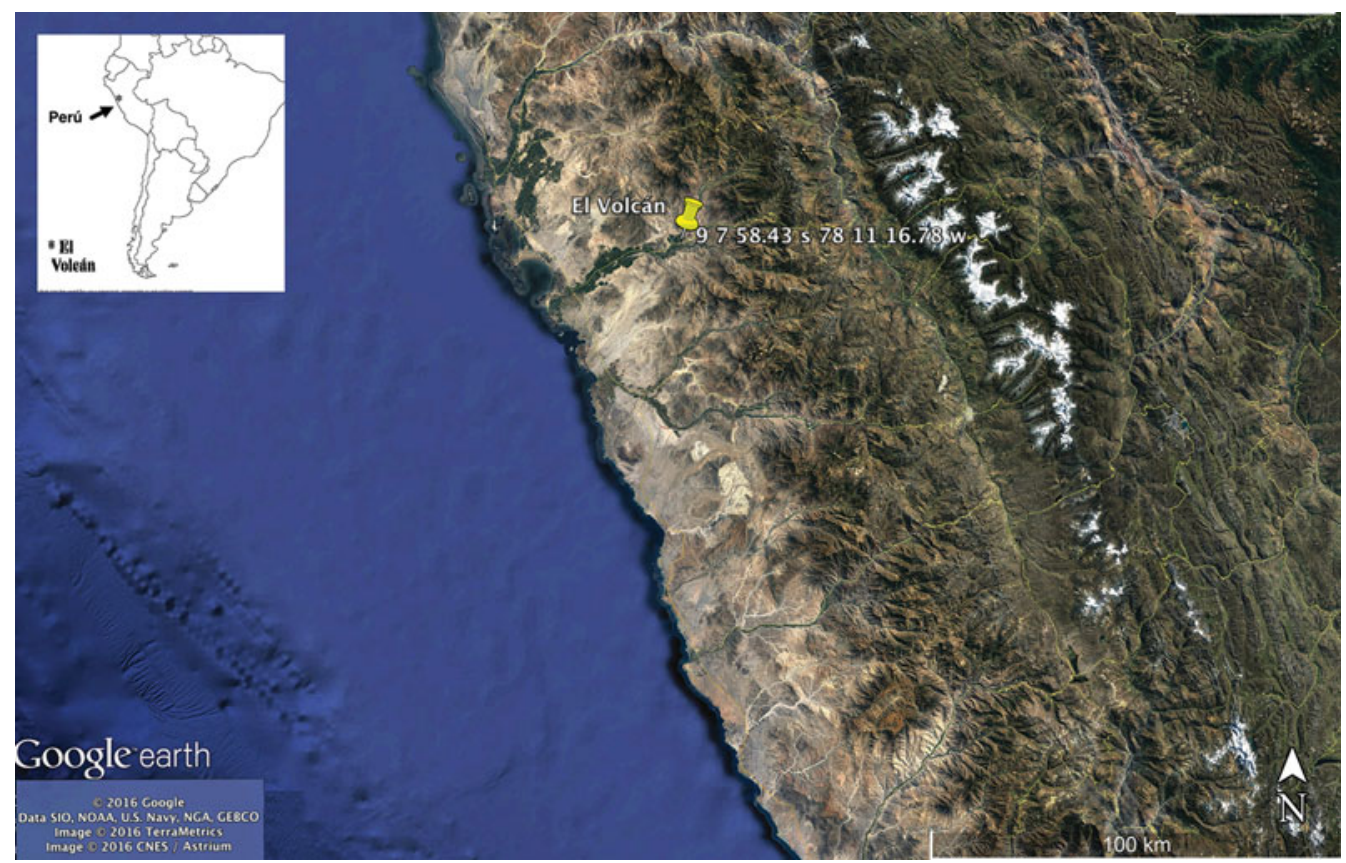

Figure 1. Location of the site.

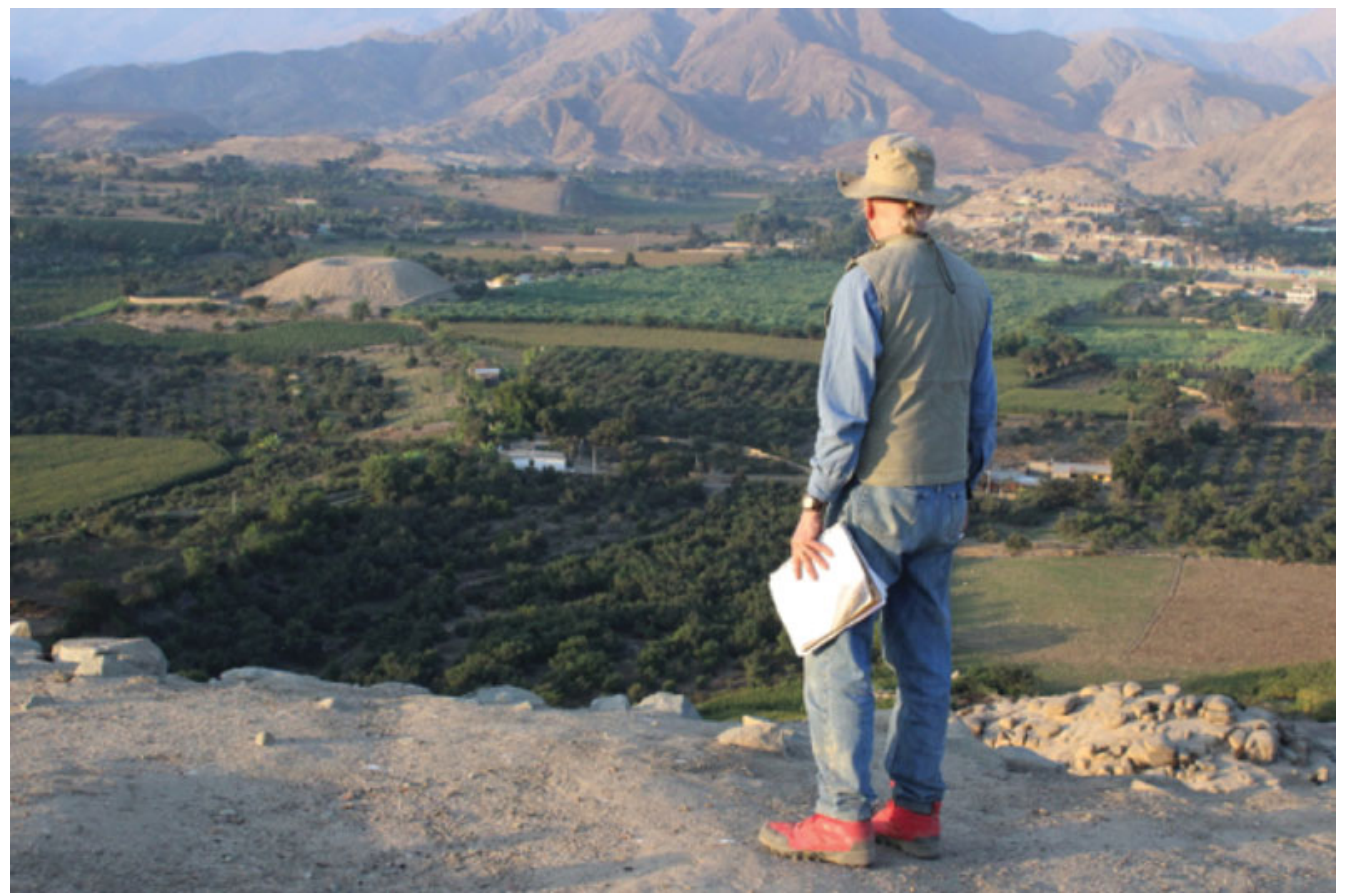

Figure 2. One of the authors (RB) looking at the site from on top of nearby San Isidrio.

(C) Antiquity Publications Ltd, 2017 


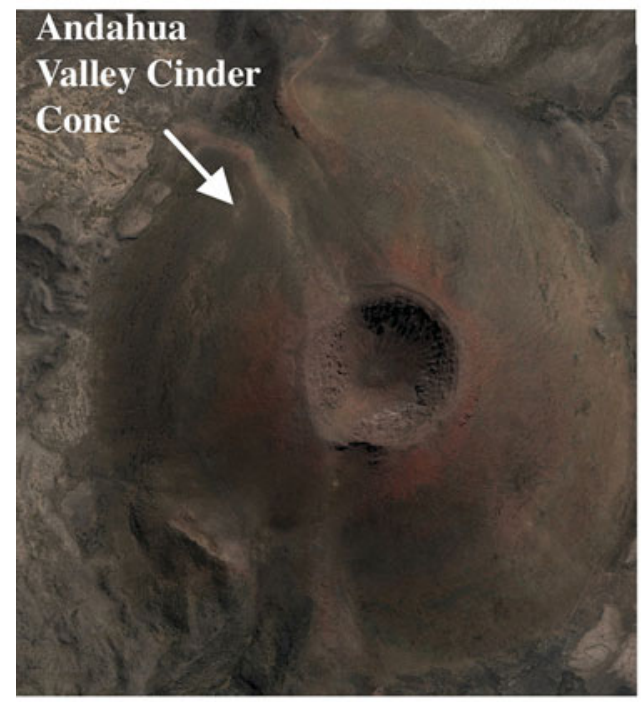

$A$

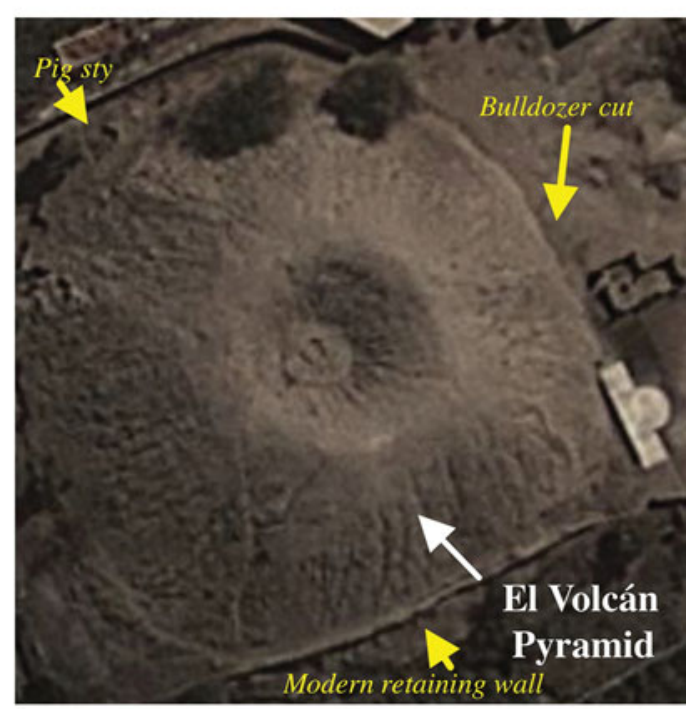

$B$

Figure 3. A cinder cone in the Andahua Valley, Peru (A), compared with the pyramid of El Volcan in the Nepeña Valley, Peru (B). Note the modern modifications to the base of El Volcán pyramid.
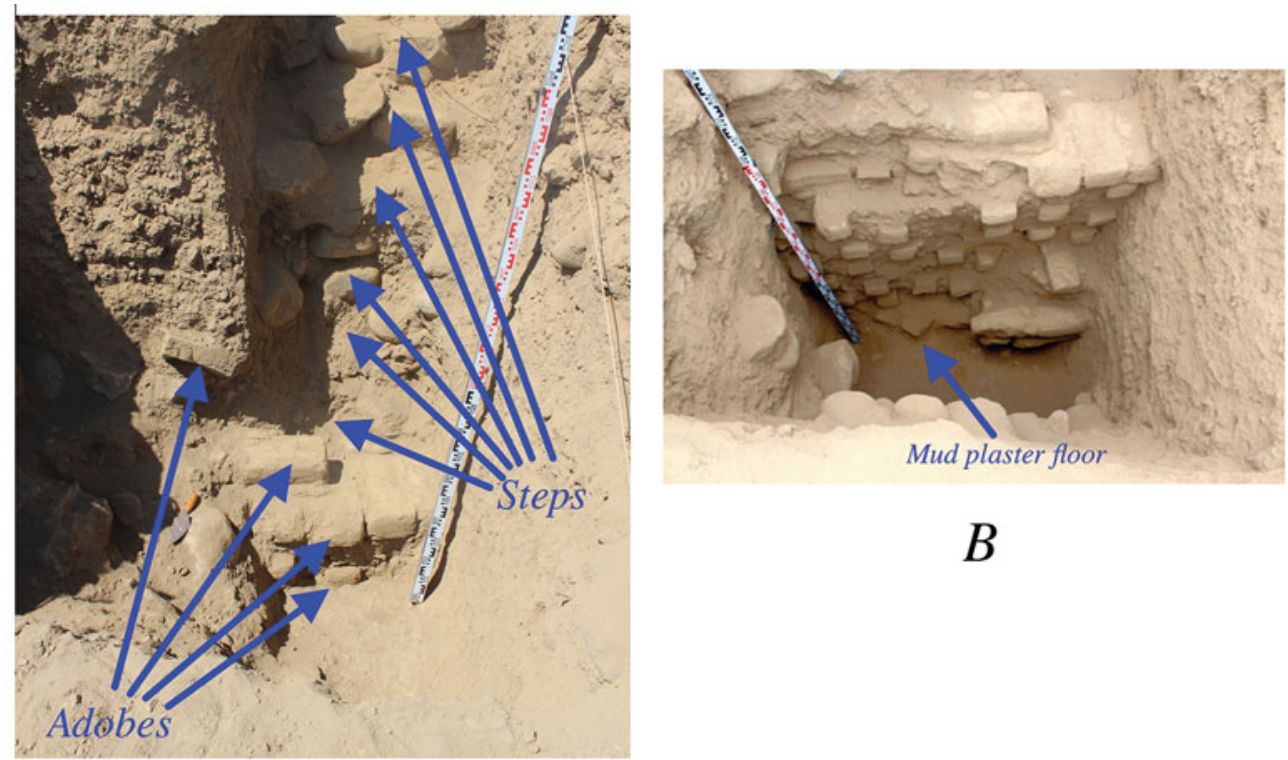

\section{$B$}

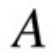

Figure 4. Photographs of trench into the south wall of El Volcán. A) stairs and large rocks in the upper part of the trench. B) fragments of a compact mud floor in the lower part of the wall trench.

(C) Antiquity Publications Ltd, 2017 


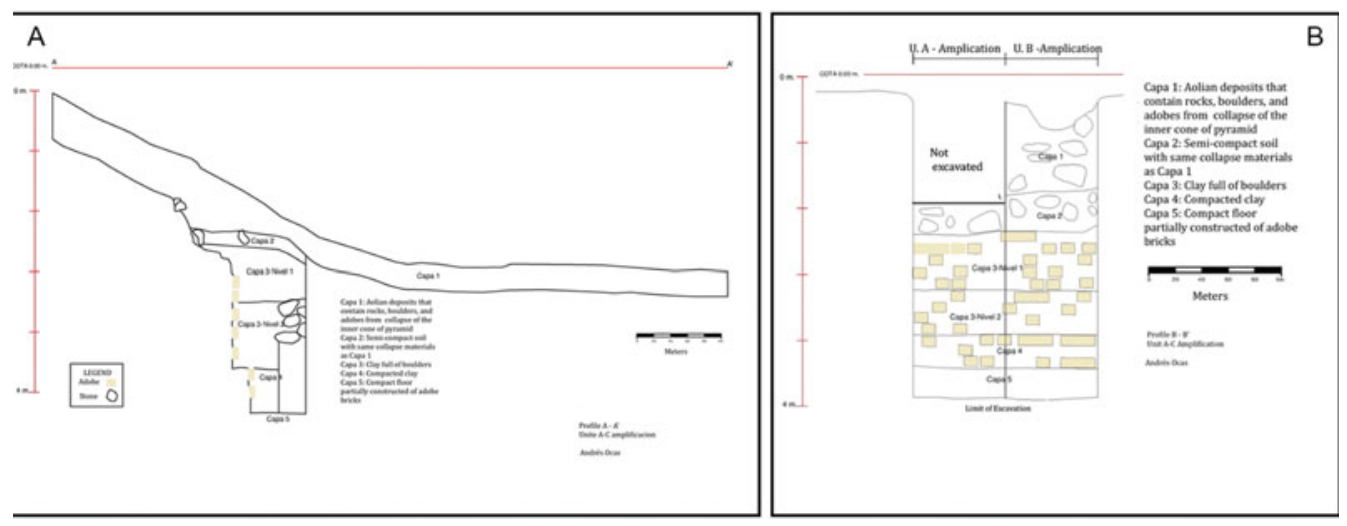

Figure 5. A) $N-S$ profile of trench into wall; B) drawing of excavation of pit cut $2 m$ into the centre of the pyramid that exposed a hearth with adobe bricks as part of its floor.

1. The excavated deposits were all laid parallel to the horizon, and were comprised of very hard caliche; any looters' pit would have been visible from our central excavation trench.

2. A looters' pit would have been unlikely to leave a perfectly horizontal base (the present surface) and to have left the caliche lenses directly below the surface undisturbed.

3. Even if looters had stopped at the present surface and somehow left it flat, they would have had to dispose of the soil. The hypothetical volume of material that would fill the central pit is $2135 \mathrm{~m}^{3}$, an amount that would surely be visible if discarded down the exterior of the pyramid (see Figure 3B).

4. The looters' pit hypothesis does not explain the conical shape of the pyramid as a whole.

5. It is possible for a rectangular earthen pyramid to be reshaped into a circular form by erosion; a much larger Mesoamerican pyramid constructed with stonewalls, La Venta, eroded into a conical exterior shape (Gonzalez Lauck 1990). There is, however, no internal cone at La Venta, and we have not found such a phenomenon at the numerous other pyramids that we have surveyed in the central coastal valleys.

On present evidence, therefore, we conclude that the pyramid was originally and deliberately constructed in the form of a volcano- a cone-shaped pyramid with a central pit (Figure 6). But why? This brings us to the final occupation of the structure and the central hearth. A radiocarbon date for the El Volcán hearth, analysed by the Centre for Applied Isotope Studies at the University of Georgia, was calibrated to a median radiocarbon date of AD 1563 by the Calib 7 program (Stuiver \& Reimer 1993; Reimer et al. 2004). As the site is located at $9^{\circ}$ south of the equator, it is unnecessary to make a southern hemisphere correction as there are no data from such a high latitude, and, in any case, the carbon dioxide should have been well mixed. This is a period of time when the calibration curve is relatively flat (Ogburn 2012), so the calibrated confidence limit is broad. Taking the 80 per cent area under the two-sigma confidence limits of the radiocarbon date, AD $320 \pm 20$, gives a calibrated range of AD 1492-1602.

Unusually, within this 110-year range was a cluster of four total solar eclipses-AD 1521, 1538, 1539 and 1543 (Stellarium 2009: 0.15.0). As total eclipses in any single location (C) Antiquity Publications Ltd, 2017 


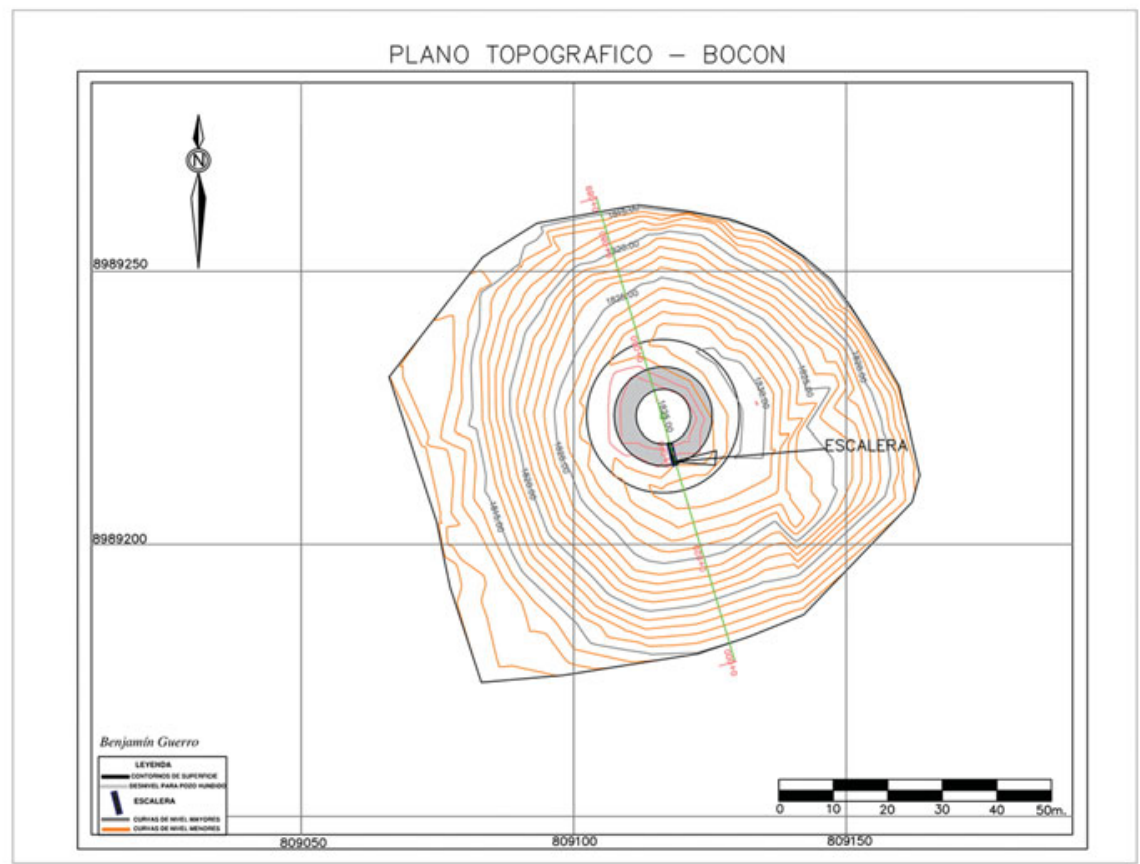

Figure 6. Total station map of pyramid. The arrow to 'escalera' (stairway) points to a modern stairway.

occur by chance about once every 360 years (Russell et al. 1926), the probability of four eclipses occurring in 110 years is 0.0003 by the Binomial Expansion. The inhabitants of the area would have had no previous experience with such a cluster. It is even less probable that four eclipses would occur in the observed range of 32 years between the eclipses of $\mathrm{AD}$ 1521 and 1543. Their appearances in so short a period would have required celebration; the people of the northern and central coasts, the Yungas, unlike the later Incas, greeted eclipse of the sun with joy, not fear (it was an eclipse of the moon that they believed called for lamentation, Eeckhout 1998: 126, 129). The median radiocarbon date of AD 1563 falls just after this cluster of eclipses, making it possible that a closing ceremony might have been linked to one of these eclipses.

One can compare the El Volcán findings with those of Buena Vista in the Chillón Valley on the Central Andean coast. At Buena Vista, a Late Preceramic feast occurred during the last recorded use of an offering chamber (Duncan et al. 2009), possibly associated with a solar eclipse. Notably, both Buena Vista and El Volcán had seashells among their remains despite their distance from the sea. Possibly the El Volcán hearth was a place celebrating the victory of the moon (and the sea) over the sun (and the land). It could also have marked the final use of this unique structure. Any ceremony at El Volcán would have been visible from the platforms at San Isidrio that align with the December solstice sunset at $246^{\circ}$ down the Nepeña Valley to the coast. 


\section{Acknowledgements}

We gratefully acknowledge the support of the Curtiss T. and Mary G. Brennan Foundation. We also acknowledge the support of Gloria Villarreal, Director of the Museo Nacional de Antropología, Biodiversidad, Agricultura y Alimentación of the Universidad Nacional Agraria—La Molina, Peru. Martín Ronald Rodriguez Huaynate was the co-director of the project. Mercedes Delgado and Yanett Cardenas contributed significantly to the investigation, as did Lucio Laura. Don Proulx graciously provided us with his notes and photographs from the original discovery. Kevin Lane and Louanna Furbee gave invaluable assistance in the organisation of this paper. We thank the proprietor, José Murillo, for his invaluable assistance. The Ministry of Culture of Peru granted permission for the excavation and monitored it.

\section{References}

Chicoine, D. \& H. Ikehara. 2014. Ancient urban life in the Nepenã Valley, north-central coast of Peru: investigations at the Early Horizon center of Caylań. Journal of Field Archaeology 39: 336-52.

Duncan, N.A., D. Pearsall \& R.A. Benfer. 2009. Gourd and squash artifacts yield starch grains of feasting foods from Preceramic Peru. Proceedings of the National Academy of Sciences of the USA 196: 13202-206. https://doi.org/10.1073/pnas.0903322106

Eескноuт, P. 1998. La renarde yunga: une fig. symbolique préhispanique. Revista Españolade Antropología Americana 28: 119-48.

Gonzales Lauck, R. 1990. The 1984 archaeological investigations at La Venta, Tabasco, México. Berkeley: University of California.

Ogburn, D.E. 2012. Reconceiving the chronology of the Inca Imperial expansion. Radiocarbon 54: 219-37. https://doi.org/10.2458/azu_js_rc.v54i2.16014

Proulx, D.A. 1968. Archaeological investigations in the Nepeña Valley, Peru. Research Reports 2. Amherst: Department of Anthropology, University of Massachusetts.
Reimer, P.J., M.G.L. Baillie, E. Bard, A. Bayliss, J.W. Beck, C.J.H. Bertrand, P.G. Blackwell, C.E. Buck, G.S. Burr, K.B. Cutler, P.E. Damon, R.L. Edwards, R.G. Fairbanks, M. Friedrich, T.P. Guilderson, A.G. Hogg, K.A. Hughen, B. Kromer, F.G. McCormac, S.W. Manning, C. Bronk Ramsey, R.W. Reimer, S. Remmele, J.R. Southon, M. Stuiver, S. Talamo, F.W. Taylor, J. van der Plicht $\&$ C.E. Weyhenmeyer. 2004. IntCal04 terrestrial radiocarbon age calibration, $26-0 \mathrm{ka} \mathrm{BP}$. Radiocarbon 46: 1029-58. http://dx.doi.org/10.1017/S0033822200032999

Russell, H.N., R.S. Dugan \& J.Q. Stewart. 1926. Astronomy (a revision of Young's Manual of astronomy). Boston (MA): Ginn \& Co.

Stellarium. 2009. Stellarium. Available at: http://www.stellarium.org/ (accessed 21 February 2017).

Stuiver, M. \& P.J. Reimer. 1993. Extended ${ }^{14} \mathrm{C}$ database and revised CALIB radiocarbon calibration program. Radiocarbon 35: 215-30. Available at: http://calib.org/calib/ (accessed 21 February 2017). http://dx.doi.org/10.1017/S0033822200013904 